\title{
Transport Process of Carbon Dioxide in Seawater and Synthetic Seawater*
}

\author{
Qiusheng LIU**, Katsuya FUKUDA** and Yongwei YANG** \\ ${ }^{* *}$ Graduate School of Maritime Sciences, Kobe University, \\ 5-1-1, Fukaeminami, Higashinada, Kobe 658-0022, Japan \\ E-mail: qsliu@maritime.kobe-u.ac.jp
}

\begin{abstract}
Carbon dioxide $\left(\mathrm{CO}_{2}\right)$ ocean sequestration technologies, such as dissolution into seawater, are important to mitigate global warming. In this study, solution processes of $\mathrm{CO}_{2}$ gas in seawater and synthetic seawater were experimentally and theoretically studied under various pressures and temperatures to evaluate the transport process of $\mathrm{CO}_{2}$ in seawater. The solubilities of $\mathrm{CO}_{2}$ in seawater and synthetic seawater were measured by a change in pressure due to absorption at temperatures ranged from $277 \mathrm{~K}$ to $333 \mathrm{~K}$ near atmospheric pressures, and ranged from $277 \mathrm{~K}$ to $298 \mathrm{~K}$ at pressures of $1 \mathrm{MPa}, 2 \mathrm{MPa}$, and $3 \mathrm{MPa}$. It was obtained that the solubilities of $\mathrm{CO}_{2}$ increase with an increase in pressure, but decrease with an increase in temperature. The solubility of $\mathrm{CO}_{2}$ in synthetic seawater decreases with an increase in salt concentration. An empirical correlation for solubility of $\mathrm{CO}_{2}$ in seawater at various temperatures and pressures was obtained based on the experimental data. In the theoretical analysis for the solution of single $\mathrm{CO}_{2}$ bubble in seawater, the single $\mathrm{CO}_{2}$ bubble was assumed to be stationary and surrounded by infinite liquid seawater. The rate of solution of bubble in liquid is affected strongly by various parameters, such as solubility, diffusion coefficient, bubble radius, and temperature.
\end{abstract}

Key words: Solution Process, Carbon Dioxide, Seawater, Synthetic Seawater, Solubility, Henry's Law Constant, Salt Concentration, Diffusion Coefficient, Bubble, Solution Time

\section{Introduction}

It is known that every year 20 billion tons of carbon dioxide $\left(\mathrm{CO}_{2}\right)$ is emitted from the industrial works and power plants, and disposed into the atmosphere due to the consumption of fossil fuel by human beings. The increasing concentration of carbon dioxide in the atmosphere is one of the causes of greenhouse effect. In order to control the concentration of $\mathrm{CO}_{2}$ in the atmosphere, technologies such as effective use of fossil fuel and conversion to clean energy are important. On the other hand, the technology of recovering the emitted $\mathrm{CO}_{2}$ and isolating from the atmosphere is also considered to be effective ${ }^{(1)}$. For example, as shown in Fig.1, after separating and collecting the $\mathrm{CO}_{2}$ gas produced from thermal power plant by the chemistry absorbing method or the physical adsorbing method, it then can be disposed into the ocean. One of the methods is to put carbon dioxide directly into the deep sea, and it is stored in the ocean by dissolving in it. It is considered that the

${ }^{*}$ Received 25 Feb., 2010 (No. 10-0100) [DOI: 10.1299/jpes.5.302]

Copyright $\odot 2011$ by JSME 
carbon dioxide gas supplied to the deep sea is isolated from the atmosphere over about 1000 years. In order to absorb and dispose the $\mathrm{CO}_{2}$ in the ocean, it is required to dissolve it into seawater, and it is necessary to investigate the solubility of $\mathrm{CO}_{2}$ in seawater at various pressures and temperatures. Furthermore, in order to analyze global-scale circulation of $\mathrm{CO}_{2}$ gas, the detailed fundamental data of solubility and diffusion coefficient are required.

Many researches ${ }^{(2),(3)}$ were reported about the solubility of the $\mathrm{CO}_{2}$ gas in pure water. However, the data of the solubility in seawater is seldom reported and not completely understood. Stewart and Munjal ${ }^{(4)}$ reported their results of solubility of $\mathrm{CO}_{2}$ in distilled water, artificial seawater in the temperature ranged from $-5{ }^{\circ} \mathrm{C}$ to $25{ }^{\circ} \mathrm{C}$ under the pressures ranged from 10 to $45 \mathrm{~atm}$. The solubility decreased with an increase in salt concentration in seawater. However, the temperature is limited and the correlation for solubility was not obtained. Weiss ${ }^{(5)}$ obtained the solubility at the temperatures ranged from $-1{ }^{\circ} \mathrm{C}$ to $40{ }^{\circ} \mathrm{C}$, the effect of pressure was not reported. Nighswander et al. ${ }^{(6)}$ obtained the experimental data of solubility for $\mathrm{CO}_{2}$ in water and $1 \mathrm{wt} \% \mathrm{NaCl}$ solution. However, the data for general seawater $(3.4 \% \mathrm{NaCl}$ solution) was not reported.

In this study, solution processes of $\mathrm{CO}_{2}$ gas in seawater and synthetic seawater were experimentally studied under various pressures, temperatures, and salt concentrations to evaluate the solubilities of $\mathrm{CO}_{2}$ in seawater. The solubilities of $\mathrm{CO}_{2}$ in seawater were measured by a change in pressure due to absorption at pressures. An empirical correlation for solubility of $\mathrm{CO}_{2}$ in seawater at various temperatures and pressures was obtained based on the experimental data. Furthermore, solution process of single $\mathrm{CO}_{2}$ bubble in seawater was theoretically studied to investigate the effects of temperature, pressure, diffusion coefficient, and initial bubble diameter on the complete solution time.

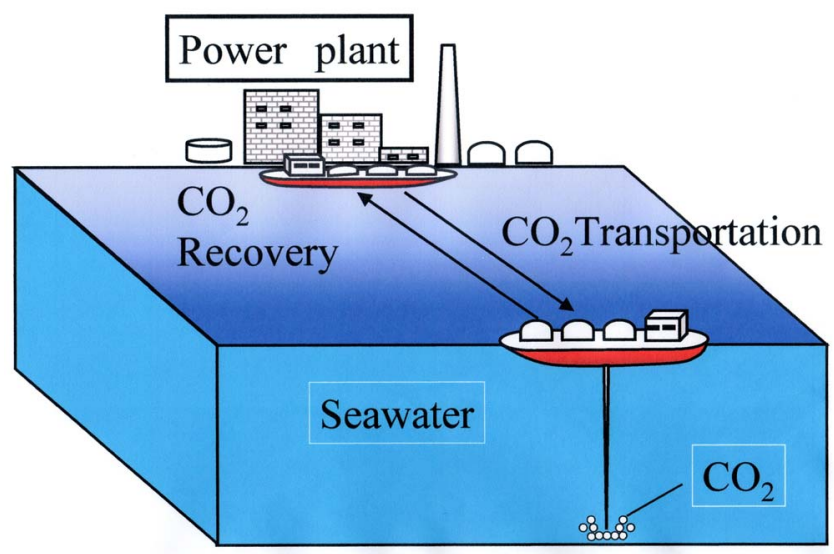

Fig.1 $\mathrm{CO}_{2}$ ocean sequestration technology.

\section{Nomenclature}

$c$ density ratio of the gas to the liquid

Dif diffusion coefficient, $\mathrm{m}^{2} / \mathrm{s}$

$\dot{G}$ mass flux at the wall of bubble

$H \quad$ Henry's law constant, $\mathrm{Pa}$

$n$ mole numbers, mole

$P$ pressure, $\mathrm{Pa}$

$R \quad$ radius of bubble, $\mathrm{m}$

$R_{0} \quad$ initial radius of bubble, $\mathrm{m}$

$\dot{R}$ decreasing rate of radius.

$r \quad$ coordinate along the radius, $\mathrm{m}$ 
$S \quad$ solubility, $\mathrm{mol} / \mathrm{m}^{3}$

$T$ temperature, $\mathrm{K}$

$t$ time, $\mathrm{s}$

$V \quad$ volume, $\mathrm{m}^{3}$

$x \quad$ solubility (mole fraction)

$\rho$ density, $\mathrm{kg} / \mathrm{m}^{3}$

$$
\begin{array}{ll}
\text { Subscripts } \\
l & \text { liquid } \\
g & \text { gas } \\
w & \text { surface of bubble }
\end{array}
$$

\section{Experimental Apparatus and Method}

Figure 2 shows the schematic diagram of the experimental apparatus. The experiments were conducted in a stainless steel vessel which is $60 \mathrm{~mm}$ in diameter, $170 \mathrm{~mm}$ in height, and $480 \mathrm{~cm}^{3}$ in volume. The gas solubilities were determined by a barometric method reported by Luhring and Schumpe ${ }^{(7)}$ and Liu et al. ${ }^{(8)}$, which involves the measurements of the volumes of the gas and liquid, the temperature, and the total pressure change due to gas absorption. Glass windows were installed for the observation and measurement of the liquid level by a CCD camera. The pressure was measured by a strain gauge pressure transducer and could be read to $\pm 0.1 \mathrm{kPa}$. The temperature was measured by K-type thermocouples with a precision of $\pm 0.5 \mathrm{deg}$. The temperature of the liquid was controlled by electric heaters installed outside of the vessel. The liquid temperature was kept constant within $\pm 1 \mathrm{deg}$ by a PID (proportion-integration-differentiation) controller. A cooling coil in the test vessel was used to lower the temperature or to obtain the experimental data at temperatures lower than room temperature.

Experiments were carried out using the following procedures: (a) the required amount of liquid (seawater or synthetic seawater) was put into the vessel; (b) the liquid was degassed by using a vacuum pump and a magnetic agitator; (c) when the temperature reached the desired value, the agitator was stopped and the $\mathrm{CO}_{2}$ gas was added slowly to reach a desired pressure; (d) when the temperatures of liquid and gas phases were equal, thermal equilibrium was reached; (e) the initial pressure, temperature, and the level of liquid were recorded; (f) agitation was started; (g) after about $10 \mathrm{~min}$, the agitation was stopped;

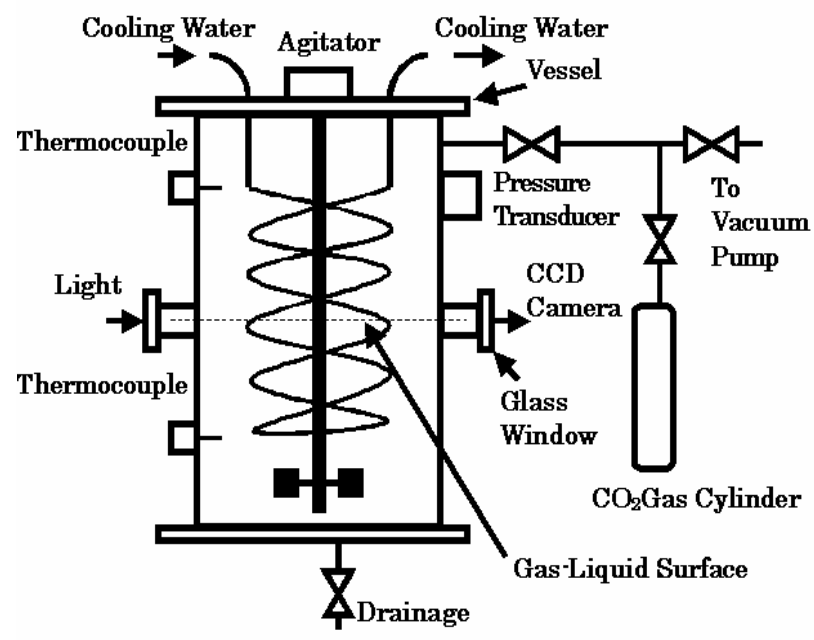

Fig.2 Schematic diagram of experimental apparatus for solubility measurement. 
the pressure would not change at the saturation state for a definite temperature; (h) the pressure and temperature were recorded, and the amount of dissolved gas was calculated.

The moles of dissolved gas were calculated by

$$
n_{2}=\frac{\Delta P_{\mathrm{CO}_{2}} V_{2}}{R^{\prime} T}
$$

where $P_{\mathrm{CO} 2}$ is the partial pressure of $\mathrm{CO}_{2}$ gas which was obtained by subtracting the seawater vapor pressure from the total pressure, $P\left(P_{a b s}\right), \Delta P_{\mathrm{CO} 2}$ is the difference of partial pressure of $\mathrm{CO}_{2}$ gas between the initial state and the final solution (saturation solution) state, $V_{2}$ is the volume of gas, $R^{\prime}$ is the gas constant $(8.314 \mathrm{~J} /(\mathrm{mol} \mathrm{K}))$, and $T$ is the absolute temperature.

The moles of seawater are

$$
n_{1}=\frac{\rho_{1} V_{1}}{M_{1}}
$$

where $\rho_{1}, V_{l}$, and $M_{l}$ are the density, the volume, and the molecular weight of seawater, respectively. Physical properties of seawater are shown in the literatures ${ }^{(3),(9)}$.

The mole fraction of dissolved gas $\left(n_{2}\right)$ in seawater $\left(n_{l}\right)$ is,

$$
x=\frac{n_{2}}{n_{1}+n_{2}}
$$

The solubility of $\mathrm{CO}_{2}$ expressed as moles of $\mathrm{CO}_{2}$ per cubic meter of seawater (in the unit of $\mathrm{mol} / \mathrm{m}^{3}$ ) is

$$
S=\frac{n_{2}}{V_{1}}
$$

Then, Henry's law constant is

$$
H=\frac{P_{\mathrm{CO}_{2}}}{x}
$$

The measurement errors for pressure, volume, and temperature were $0.2 \%, 0.2 \%$, and $0.75 \%$, respectively. Then, the measurement errors for $n_{2}, x$, and $H$ were estimated to be about $1.5 \%$. The reproducibility of solubility was with $\pm 5 \%$ for triplicate measurements.

\section{Experimental Results and Discussion}

The experimental data were obtained at temperatures ranged from 277 to $298 \mathrm{~K}$, and the pressures ranged from around $1 \mathrm{MPa}$ to $3 \mathrm{MPa}$. Moreover, the temperatures ranged from $277 \mathrm{~K}$ to $333 \mathrm{~K}$ at pressures near atmospheric pressures.

In the measurement of solubility, to clarify the reliability of the experiment and procedure, the solubility for $\mathrm{CO}_{2}$ in pure water was also measured and compared with 
previous data. Figure 3 illustrates the Henry's law constants calculated from the experimental data of solubility for $\mathrm{CO}_{2}$ in pure water under pressures from near atmospheric pressure up to $200 \mathrm{kPa}$. The dashed line shows the data reported by Hodgman ${ }^{(10)}$. It can be seen that the experimental data of pure water shows good agreement with the data tabulated by Hodgman ${ }^{(10)}$ : they are increasing with the increase of temperature. On the other hand, the Henry's law constants of $\mathrm{CO}_{2}$ in pure water show lower values compared with those in seawater near atmospheric pressure as shown in the figure.

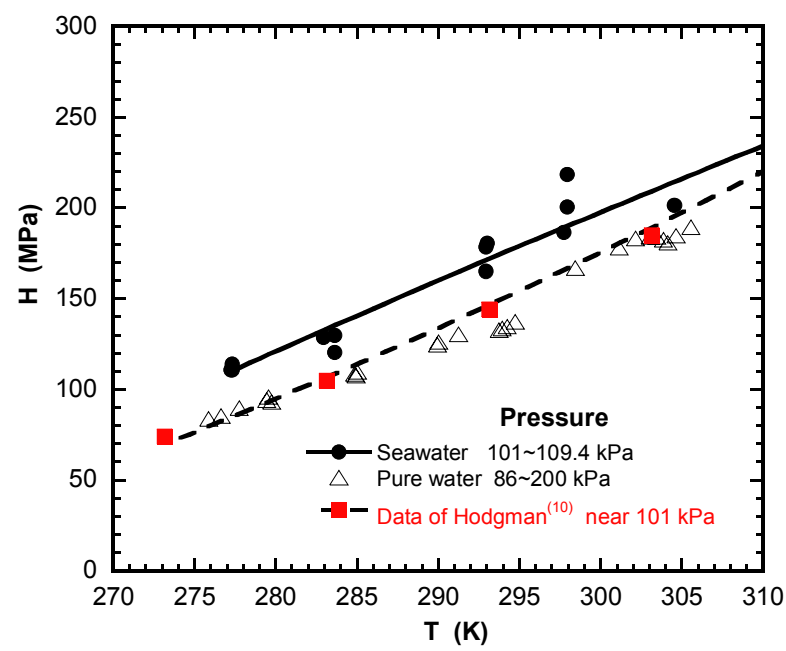

Fig. 3 Henry's law constants of $\mathrm{CO}_{2}$ in pure water and seawater.

Table 1 Solubility of $\mathrm{CO}_{2}$ in seawater at pressures from $101 \mathrm{kPa}$ to $157 \mathrm{kPa}$.

\begin{tabular}{|c|c|c|c|c|}
\hline $\begin{array}{c}P_{a b s} \\
{[\mathrm{kPa}]}\end{array}$ & $\begin{array}{c}T \\
{\left[{ }^{\circ} \mathrm{C}\right]}\end{array}$ & $\begin{array}{c}P_{\mathrm{CO} 2} \\
{[\mathrm{kPa}]}\end{array}$ & $\begin{array}{c}x \\
{\left[10^{-3}\right]}\end{array}$ & $\begin{array}{c}S \\
{\left[\mathrm{~mol} / \mathrm{m}^{3}\right]}\end{array}$ \\
\hline 103.8 & 4.2 & 102.9 & 0.93 & 52.3 \\
\hline 105.7 & 4.2 & 104.8 & 0.92 & 51.6 \\
\hline 103.8 & 4.1 & 102.9 & 0.93 & 52.4 \\
\hline 107.3 & 10.5 & 105.9 & 0.88 & 49.4 \\
\hline 106.3 & 10.5 & 104.9 & 0.81 & 45.2 \\
\hline 106.7 & 9.8 & 105.5 & 0.82 & 46.0 \\
\hline 102.4 & 19.8 & 100.0 & 0.56 & 31.6 \\
\hline 103.4 & 19.9 & 101.0 & 0.56 & 31.4 \\
\hline 101.4 & 19.8 & 99.0 & 0.60 & 33.9 \\
\hline 109.4 & 24.6 & 106.3 & 0.57 & 31.8 \\
\hline 109.4 & 24.8 & 106.2 & 0.53 & 29.8 \\
\hline 107.6 & 25.0 & 104.1 & 0.48 & 38.6 \\
\hline 139.6 & 31.4 & 134.9 & 0.67 & 37.7 \\
\hline 157.2 & 38.7 & 150.4 & 0.65 & 36.5 \\
\hline 142.5 & 40.2 & 135 & 0.56 & 31.4 \\
\hline 139.6 & 47.3 & 129.1 & 0.49 & 27.2 \\
\hline 136.6 & 48.6 & 125.6 & 0.45 & 25 \\
\hline 139.6 & 54.5 & 124.7 & 0.41 & 22.8 \\
\hline 153.3 & 59.5 & 135.7 & 0.46 & 25.7 \\
\hline 134.7 & 62.2 & 114 & 0.34 & 19.1 \\
\hline
\end{tabular}


Table 2 Solubility of $\mathrm{CO}_{2}$ in seawater near $1 \mathrm{MPa}$.

\begin{tabular}{|c|c|c|c|c|}
\hline $\begin{array}{c}P_{a b s} \\
{[\mathrm{kPa}]}\end{array}$ & $\begin{array}{c}T \\
{\left[{ }^{\circ} \mathrm{C}\right]}\end{array}$ & $\begin{array}{c}P_{C O 2} \\
{[\mathrm{kPa}]}\end{array}$ & $\begin{array}{c}x \\
{\left[10^{-3}\right]}\end{array}$ & $\begin{array}{c}S \\
{\left[\mathrm{~mol} / \mathrm{m}^{3}\right]}\end{array}$ \\
\hline 1034.0 & 4.2 & 1033.0 & 8.24 & 476.1 \\
\hline 1025.1 & 4.4 & 1024.2 & 8.10 & 468.1 \\
\hline 997.7 & 4.4 & 996.7 & 7.84 & 451.9 \\
\hline 1103.6 & 10.2 & 1102.2 & 7.42 & 423.5 \\
\hline 1029.1 & 10.0 & 1027.7 & 7.74 & 443.0 \\
\hline 1005.5 & 10.2 & 1004.2 & 7.55 & 433.1 \\
\hline 1031.6 & 20.0 & 1029.2 & 5.37 & 304.8 \\
\hline 1045.3 & 20.1 & 1042.9 & 5.40 & 308.2 \\
\hline 1020.8 & 20.1 & 1018.4 & 5.31 & 300.6 \\
\hline 995.4 & 25.2 & 992.1 & 4.54 & 258.5 \\
\hline 983.6 & 25.2 & 980.3 & 4.55 & 258.2 \\
\hline 972.8 & 25.2 & 969.5 & 4.47 & 253.4 \\
\hline
\end{tabular}

Table 3 Solubility of $\mathrm{CO}_{2}$ in seawater near $2 \mathrm{MPa}$.

\begin{tabular}{|c|c|c|c|c|}
\hline $\begin{array}{c}P_{a b s} \\
{[\mathrm{kPa}]}\end{array}$ & $\begin{array}{c}T \\
{\left[{ }^{\circ} \mathrm{C}\right]}\end{array}$ & $\begin{array}{c}P_{\mathrm{CO} 2} \\
{[\mathrm{kPa}]}\end{array}$ & $\begin{array}{c}x \\
{\left[10^{-3}\right]}\end{array}$ & $\begin{array}{c}S \\
{\left[\mathrm{~mol} / \mathrm{m}^{3}\right]}\end{array}$ \\
\hline 2026.0 & 4.0 & 2025.2 & 12.6 & 730.8 \\
\hline 2072.1 & 4.3 & 2071.2 & 12.3 & 713.8 \\
\hline 1974.0 & 4.3 & 1973.2 & 12.0 & 693.3 \\
\hline 2004.7 & 10.2 & 2003.4 & 10.2 & 593.1 \\
\hline 1947.1 & 10.3 & 1945.8 & 10.4 & 614.3 \\
\hline 2007.0 & 10.3 & 2005.6 & 10.0 & 586.2 \\
\hline 1945.0 & 19.9 & 1942.6 & 8.44 & 487.8 \\
\hline 1942.0 & 20.0 & 1939.6 & 8.27 & 477.0 \\
\hline 1962.6 & 20.0 & 1960.2 & 8.23 & 474.6 \\
\hline 1945.6 & 25.4 & 1942.4 & 7.72 & 441.2 \\
\hline 2072.5 & 25.2 & 2069.2 & 7.78 & 447.6 \\
\hline
\end{tabular}

Table 4 Solubility of $\mathrm{CO}_{2}$ in seawater near $3 \mathrm{MPa}$.

\begin{tabular}{|c|c|c|c|c|}
\hline $\begin{array}{c}P_{a b s} \\
{[\mathrm{kPa}]}\end{array}$ & $\begin{array}{c}T \\
{\left[{ }^{\circ} \mathrm{C}\right]}\end{array}$ & $\begin{array}{c}P_{\mathrm{CO} 2} \\
{[\mathrm{kPa}]}\end{array}$ & $\begin{array}{c}x \\
{\left[10^{-3}\right]}\end{array}$ & $\begin{array}{c}S \\
{\left[\mathrm{~mol} / \mathrm{m}^{3}\right]}\end{array}$ \\
\hline 2890.2 & 9.6 & 2888.9 & 11.4 & 671.3 \\
\hline 2875.5 & 9.7 & 2874.2 & 11.6 & 684.2 \\
\hline 3043.1 & 9.6 & 3041.8 & 11.3 & 659.8 \\
\hline 3043.3 & 20.0 & 3040.9 & 9.97 & 567.0 \\
\hline 3024.7 & 20.3 & 3022.2 & 9.58 & 558.0 \\
\hline 3012.9 & 20.1 & 3010.4 & 9.81 & 570.5 \\
\hline 2982.9 & 25.2 & 2979.6 & 9.39 & 543.3 \\
\hline 2960.3 & 25.3 & 2957.0 & 9.09 & 526.3 \\
\hline 3084.9 & 25.2 & 3081.6 & 9.13 & 533.4 \\
\hline
\end{tabular}


Table 1 shows the solubility, $S$, in the unit of $\mathrm{mol} / \mathrm{m}^{3}$, and the mole fraction solubility, $x$, of $\mathrm{CO}_{2}$ in seawater at pressures from $101 \mathrm{kPa}$ to $157 \mathrm{kPa}$ at temperatures ranged from 4.1 ${ }^{\circ} \mathrm{C}$ to $62.2{ }^{\circ} \mathrm{C}(277 \mathrm{~K}$ to $335 \mathrm{~K})$. All the pressures are taken from values at saturated solution condition. The mole fraction solubility increases from $0.34 \times 10^{-3}$ to $0.93 \times 10^{-3}$ with decreasing temperatures from $335 \mathrm{~K}$ to $277 \mathrm{~K}$. The solubility per unit volume, $S$, shows the same trend with mole fraction solubility, it increases from $19.1 \mathrm{~mol} / \mathrm{m}^{3}$ to $52.4 \mathrm{~mol} / \mathrm{m}^{3}$ with the decrease of temperature. Tables 2,3 , and 4 show the solubilities of $\mathrm{CO}_{2}$ in seawater at pressures near $1 \mathrm{MPa}, 2 \mathrm{MPa}$, and $3 \mathrm{MPa}$, respectively.

Figure 4 shows the mole fraction solubilities, $x$, at various pressures for the temperatures ranged from $277 \mathrm{~K}$ to $298 \mathrm{~K}$. It is understood that the solubilities increase with an increase in pressure, and decrease with an increase in temperature.

Figure 5 shows the solubilities, $S$, at temperatures of $283 \mathrm{~K}$ and $298 \mathrm{~K}$ under various pressures. The data by Stewart and Munjal ${ }^{(4)}$, and Broecker ${ }^{(11)}$ are also shown in the figure for comparison. As shown in the figure, almost all the experimental data agree well with the data by Stewart and Munjal ${ }^{(4)}$, and Broecker ${ }^{(11)}$ within $-4 \%$ to $8 \%$ except the data at $283 \mathrm{~K}$ under $2 \mathrm{MPa}$ : the experimental data are $16 \%$ lower than Stewart and Munjal's data ${ }^{(4)}$ at 283 $\mathrm{K}$ and $2 \mathrm{MPa}$. As reported by Stewart and Munjal ${ }^{(4)}$, they used an experimental apparatus

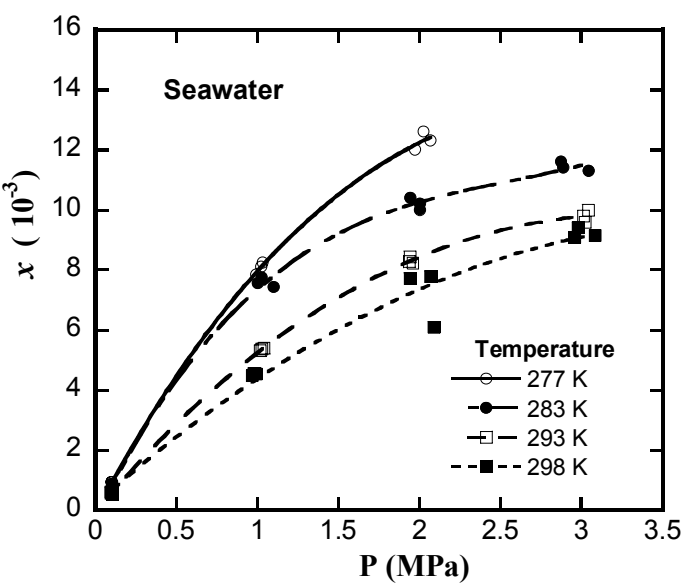

Fig.4 Solubilities at various pressures and temperatures.

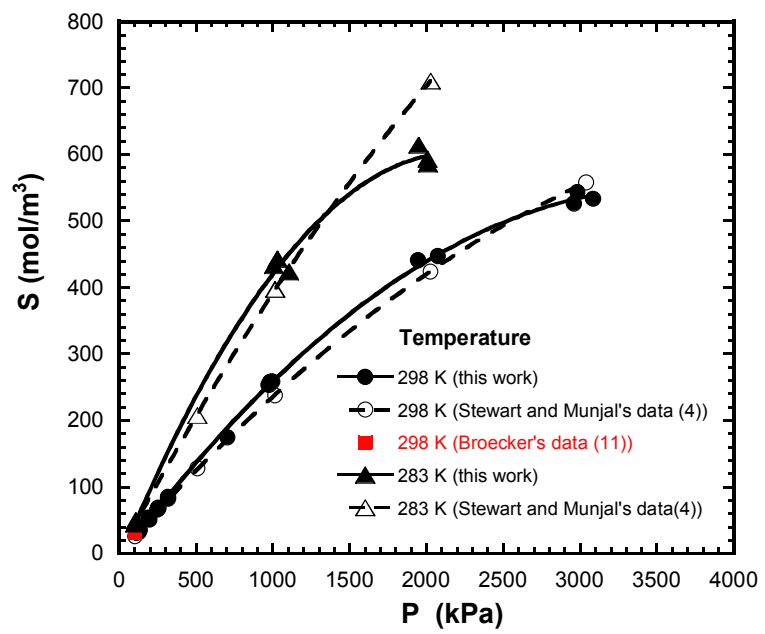

Fig.5 Comparison of the author's experimental data with the data by Stewart and Munjal ${ }^{(4)}$, and Broecker ${ }^{(11)}$. 


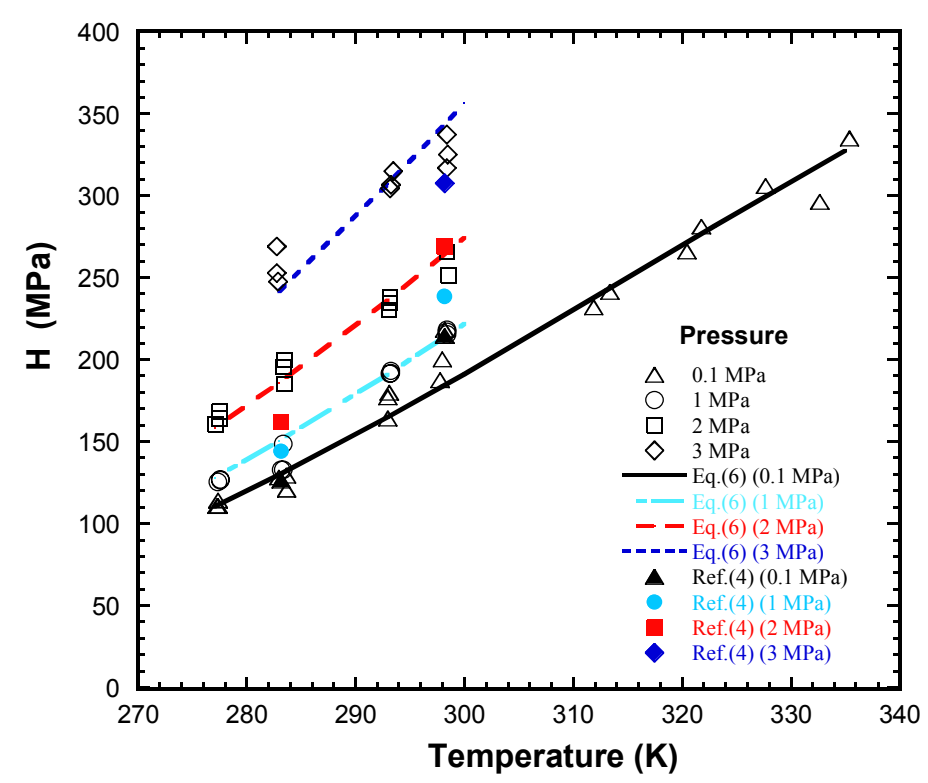

Fig.6 Henry's law constants of $\mathrm{CO}_{2}$ in seawater at various temperatures and pressures.

consisting of an autoclave, a liquid sample-withdrawal and chemical analysis instrument. On the other hand, in the present work, the authors used a barometric method by measuring the changes in pressures due to the absorption of $\mathrm{CO}_{2}$ in seawater. The difference between authors' data with those by Stewart and Munjal is considered to be arising from the difference in the experimental method.

Figure 6 shows Henry's law constants for $\mathrm{CO}_{2}$ in seawater at various pressures and temperatures. They are calculated from the experimental data tabulated in Tables 1 to 4 . As shown in Fig.6, the Henry's law constants increase with the increases in pressures and temperatures. It should be noted that the correlation for Henry's law constant at a high pressure should take into account the effect of pressure as reported by Liu et al. in the previous paper ${ }^{(8)}$. An empirical correlation based on authors' experimental data at various pressures and temperatures was obtained as following equation.

$$
\ln \left(\frac{H}{H_{0}}\right)=A\left(1-\frac{T_{0}}{T}\right)+B \ln \left(\frac{T}{T_{0}}\right)+C\left(\frac{T}{T_{0}}-1\right)+f(P)
$$

where, $H(\mathrm{MPa}), T(\mathrm{~K})$ are the Henry's law constant and the temperature, respectively. And, $f(P)=m_{1} P^{2}+m_{2} P+m_{3}, P(\mathrm{MPa})$ is system pressure, $A=27.54, \quad B=-27.0, \quad C=5.60$, $H_{0}=187.6 \mathrm{MPa}, T_{0}=298.15 \mathrm{~K}, m_{l}=0.025, m_{2}=0.137, m_{3}=-0.0317$.

The calculated values by Eq.(6) are also shown in Fig.6 as solid and dashed lines. They agree with author's experimental data within $\pm 6 \%$. The data obtained from Stewart and Munjal (4) are also shown in the same figure for comparison. It is understood that the correlation can express their data within $\pm 15 \%$.

To investigate the effect of salt concentration on the solubility, experiments were carried out using several kinds of synthetic seawater with different weight concentration of $\mathrm{NaCl}$ solution. Figure 7 shows solubilities at a temperature of $283 \mathrm{~K}$ for salt concentrations ranged from $1 \mathrm{wt} \%$ up to $5 \mathrm{wt} \%$. The data for seawater $(3.4 \mathrm{wt} \%)$ was shown in the same figure for comparison. We can see the solubilities decrease with an increase in salt concentration. It is fruitful to have a check on previous data at other salt concentrations. 
Stewart and Munjal ${ }^{(4)}$ reported some data at salt concentrations of $3.4 \mathrm{wt} \%, 10.3 \mathrm{wt} \%$, and $17.2 \mathrm{wt} \%$ at a temperature of $283 \mathrm{~K}$ under $1 \mathrm{MPa}$. Their data are shown in Fig.7 by solid symbols for reference. We can see their data show the same dependence on salt concentration: the solubility decreases with an increase in salt concentration. As can be seen from the figure, their data are lower than the authors' data due to their higher salt concentrations. We can obtain the similar result if we compare Stewart and Munjal's data with author's experimental data at other temperatures such as $277 \mathrm{~K}, 293 \mathrm{~K}$ for salt concentration of $4 \%$. It is considered that the solubilities at various salt concentrations and temperatures measured in this wok are reasonable.

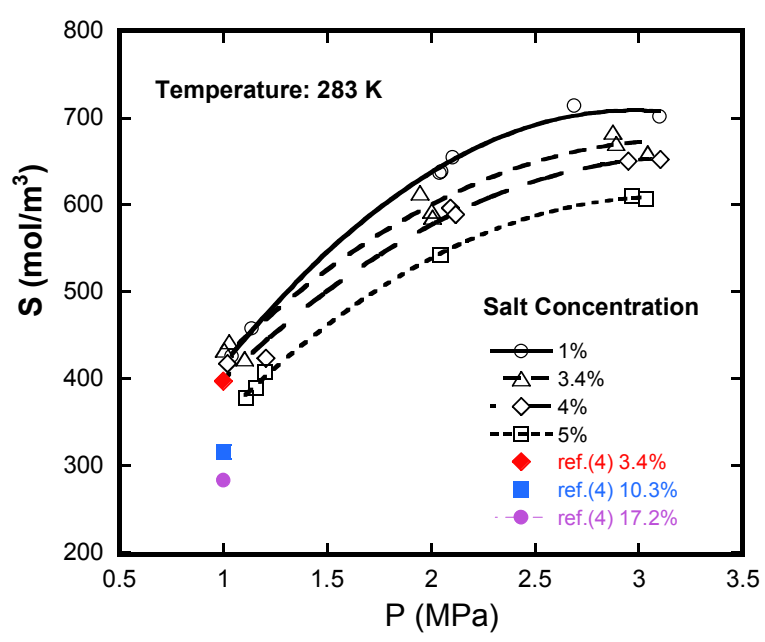

Fig.7 Solubilities of $\mathrm{CO}_{2}$ in seawater and synthetic seawater at various salt concentrations.

\section{Theoretical Study of Solution and Diffusion Process for Single $\mathrm{CO}_{2}$ Bubble in Liquid Seawater}

As explained in the introduction of this research, in order to dispose the $\mathrm{CO}_{2}$ in the ocean, it is necessary to dissolve it into seawater by a method of bubble solution through a nozzle (see Fig.1). In this section, solution process of single $\mathrm{CO}_{2}$ bubble in seawater is numerically solved to investigate the effects of parameters such as temperature, pressure, diffusion coefficient, and initial bubble diameters on the complete solution time. As the first stage of this study, we just deal with the normal standard seawater (salt concentration 3.4\%) in this solution. The solubilities measured at various pressures and temperatures in this work are used in the numerical solution.

\subsection{Basic Equation and Boundary Condition}

Figure 8 shows the physical model for single $\mathrm{CO}_{2}$ bubble solution in seawater. The physical model is the same with that in authors' previous analysis ${ }^{(12),(13)}$. Following assumptions are made to obtain theoretical solutions.

(1) Bubble is spherical and stationary in the liquid.

(2) The concentration of $\mathrm{CO}_{2}$ gas at the gas-liquid interface is governed by Henry's law.

(3) Surface tension in the gas-liquid boundary is neglected.

According to the above assumptions, the mass conservation equation for $\mathrm{CO}_{2}$ gas in liquid is as follows:

$$
\frac{\partial \rho_{g}}{\partial t}+\frac{1}{r^{2}} \frac{\partial}{\partial r}\left(r^{2} \rho_{g} u_{g}\right)=0
$$




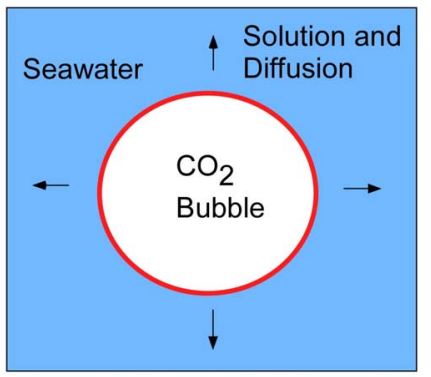

Fig.8 Physical model of single $\mathrm{CO}_{2}$ bubble solution and diffusion in seawater.

where, one-dimensional spherical coordinate is used, $r$ is coordinate along the radius, $t$ is time, $\rho_{g}$ is density of the gas, and $u_{g}$ is velocity of gas in the liquid. $u_{g}$ is expressed by the following equations ${ }^{(12),(13)}$ :

$$
u_{g}=\frac{R^{2}}{r^{2}} \dot{R}-\frac{\rho_{l}}{\rho_{g}} \text { Dif } \frac{\partial}{\partial r}\left[\frac{\rho_{g}}{\rho_{l}}\right]
$$

where, $\rho_{l}, R, \dot{R}$ and $D i f$ are density of liquid, radius of bubble, decreasing rate of radius, and diffusion coefficient.

Substituting Eq.(8) into Eq.(7), and dividing by $\rho_{l}$, we have,

$$
\frac{\partial c}{\partial t}+\frac{1}{r^{2}} \frac{\partial}{\partial r}\left(c \dot{R} R^{2}-r^{2} \text { Dif } \frac{\partial c}{\partial r}\right)=0
$$

where, $c$ is the density ratio of the gas to the liquid.

Boundary conditions are:

$$
\begin{array}{ll}
r \rightarrow \infty, & c_{\infty}=0 \\
r=R, & c_{w}=P_{c o} / H \\
r=R, & \dot{G}=\rho_{g i} \dot{R}=\rho_{l} \text { Dif }\left[\frac{\partial c}{\partial r}\right]_{w}
\end{array}
$$

where, $H$ is Henry's law constant evaluated by Eq.(11) when solubility is used as weight concentration, $c_{w}$ is the density ratio at the wall of bubble, $P_{c o}$ is pressure of the bubble, $\rho_{g i}$ is density of the gas within the bubble, and $\dot{G}$ is mass flux at the interface of bubble.

Using dimensionless variables determined by Eq.(13), Eq.(9) is expressed as dimensionless form shown in Eq.(14):

$$
\begin{aligned}
& t^{*}=\frac{\text { Dif }}{R_{0}{ }^{2}} t, \quad R^{*}=\frac{R}{R_{0}}, \quad r^{*}=\frac{r}{R_{0}}, \quad c^{*}=\frac{c}{c_{w}} \\
& \frac{\partial c^{*}}{\partial t^{*}}+\frac{1}{r^{* 2}} \frac{\partial}{\partial r^{*}}\left(c^{*} \dot{R} * R^{* 2}-r^{* 2} \frac{\partial c^{*}}{\partial r^{*}}\right)=0
\end{aligned}
$$

where, $R_{0}$ is initial radius of $\mathrm{CO}_{2}$ bubble. Boundary conditions are transformed into, 


$$
c_{w}^{*}=1, \quad c_{\infty}^{*}=0, \quad \dot{R}^{*}=\frac{1}{b}\left[\frac{\partial c^{*}}{\partial r^{*}}\right]_{w}
$$

where,

$$
b=\frac{\rho_{g i}}{\rho_{l} c_{w}}
$$

As shown in Eqs.(15) and (16), the solution and diffusion process is governed by the parameter $b$.

$$
c_{w}=\frac{P c O_{2}}{H}=\frac{\rho_{g i} R^{\prime} T}{H}, \quad b=\frac{H}{\rho_{l} R^{\prime} T}
$$

then $c_{w}$ is proportional to $\rho_{g i}$, and the process is governed by various variables such as temperature, diffusion coefficient, solubility, and initial radius.

The Eq.(14) was numerically solved by finite difference method.

\subsection{Results of Numerical Solution}

Figure 9 shows the solution and diffusion process of the single $\mathrm{CO}_{2}$ bubble in seawater at temperatures of $277 \mathrm{~K}, 283 \mathrm{~K}$, and $293 \mathrm{~K}$. The system pressure is $0.1 \mathrm{MPa}$. Henry's law constants measured by authors at the corresponding temperatures of $277 \mathrm{~K}$, $283 \mathrm{~K}$, and $293 \mathrm{~K}$ are $110 \mathrm{MPa}, 126 \mathrm{MPa}$, and $158 \mathrm{MPa}$, respectively. And the diffusion coefficients at the corresponding temperatures are $1.03 \times 10^{-9} \mathrm{~m}^{2} / \mathrm{s}, 1.24 \times 10^{-9} \mathrm{~m}^{2} / \mathrm{s}$, and $1.63 \times 10^{-9} \mathrm{~m}^{2} / \mathrm{s}$, respectively ${ }^{(14),(15)}$. Densities for seawater are $1028 \mathrm{~kg} / \mathrm{m}^{3}$ at $277 \mathrm{~K}, 1028$ $\mathrm{kg} / \mathrm{m}^{3}$ at $283 \mathrm{~K}$, and $1026 \mathrm{~kg} / \mathrm{m}^{3}$ at $293 \mathrm{~K} . \mathrm{b}$ are obtained as $0.8574,0.9616$, and 1.1645 at the corresponding temperatures based on Eq.(16).

The ordinate of Fig.9 is the dimensionless radius, and the abscissa is the dimensionless time. The solid line and the dashed lines show the results at various temperatures. As shown in the figure, the total solution time is $30 \%$ shorter at $277 \mathrm{~K}$ than that at $293 \mathrm{~K}$. This means that the solution process is enhanced by lowering the temperature.

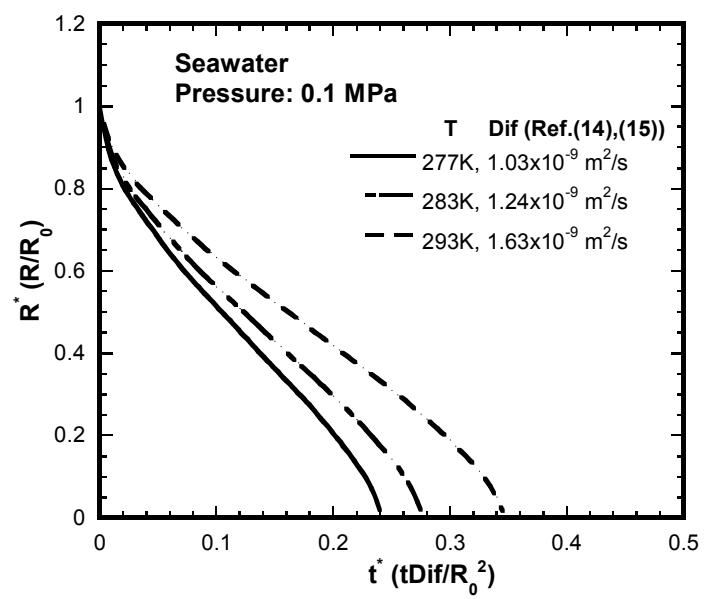

Fig. 9 Theoretical solutions of nondimensional radius-time relation for single $\mathrm{CO}_{2}$ bubble solution in seawater. 
Figures 10(a)-(c) are numerical solution results for dimensionless radius-time relation for single $\mathrm{CO}_{2}$ bubble solution in seawater at pressures of $1 \mathrm{MPa}(\mathrm{a}), 2 \mathrm{MPa}$ (b) and $3 \mathrm{MPa}$ (c). It can be seen from Figs. 10(a)-(c) that the dimensionless complete solution time at a definite temperature becomes larger as the pressure increased.

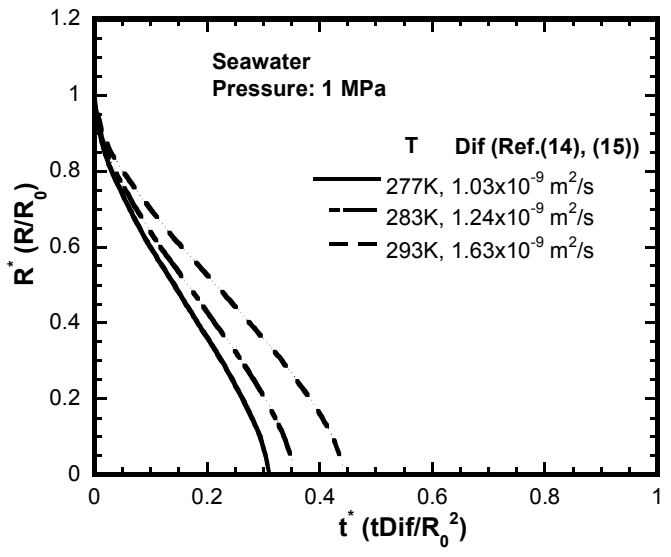

(a) $1 \mathrm{MPa}$

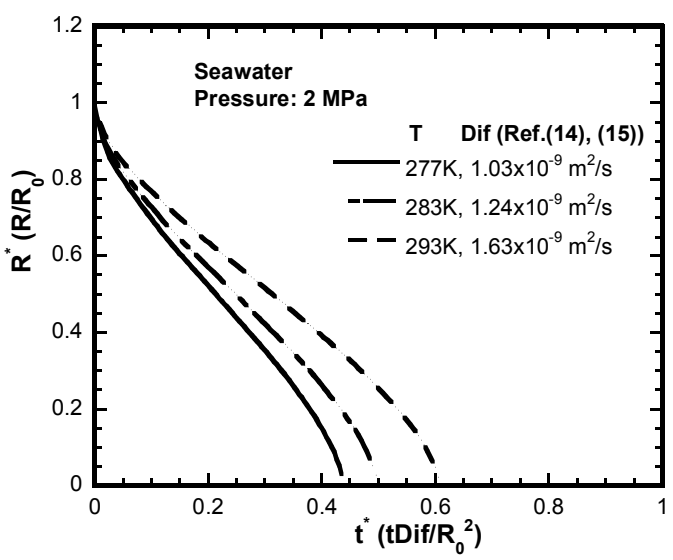

(b) $2 \mathrm{MPa}$

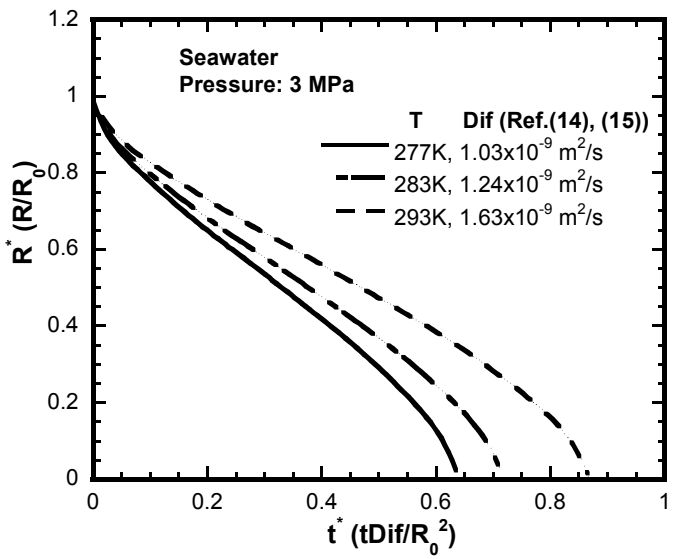

(c) $3 \mathrm{MPa}$

Fig. 10 Theoretical solutions of nondimensional radius-time relation for single $\mathrm{CO}_{2}$ bubble solution in seawater. 
As shown in Eqs.(15), and (16), the solution process is governed by parameter $b$. Henry's law constant is a function of temperature, and $b$ is also determined by temperature. As shown in Figs.9 and 10, the solution time decreased with a decrease in temperature as can be derived from Eq.(15) because the value of $b$ decreased with the increase of temperature.

On the other hand, according to correlation (Eq.(6)), Henry's law constant increases with the pressure, then the value of $\mathrm{b}\left(b=H /\left(\rho_{l} R^{\prime} T\right)\right)$ will increase with the pressure. As the result, the solution time increased with the pressure as shown in Figs. 10(a)-(c).

We can derive from Fig.10 that the complete solution time will increase with an increase in initial diameter (or radius) because the dimensional time, $t\left(t=t^{*} R_{0}{ }^{2} / D i f\right)$, is proportional to the square of bubble radius as well as the nondimensional time, $t^{*}$.

Figure 11 shows the comparison of solution time for seawater with pure water. Seawater needs more time because of its lower solubility compared with that of pure water.

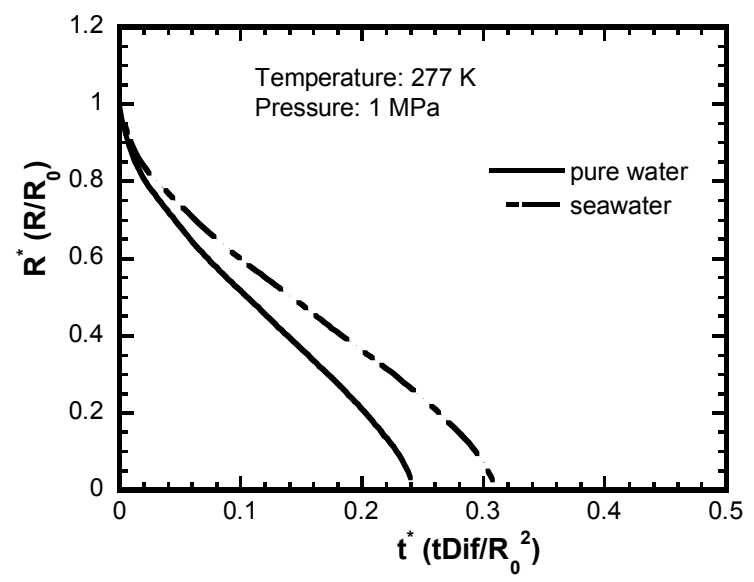

Fig. 11 Comparison of solution process with pure water.

\section{Conclusions}

Solution processes of $\mathrm{CO}_{2}$ gas in seawater and synthetic seawater were experimentally studied under various pressures, temperatures, and salt concentrations to evaluate the solubilities of $\mathrm{CO}_{2}$ in seawater. Moreover, solution time for single $\mathrm{CO}_{2}$ bubble in seawater was numerically obtained. Following results were obtained.

(1) The experimental data agree well with Stewart and Munjal's data ${ }^{(4)}$ within $-4 \%$ to $8 \%$ except the data at $2 \mathrm{MPa}$ and $283 \mathrm{~K}$.

(2) An empirical correlation for solubilities of $\mathrm{CO}_{2}$ in seawater at various temperatures ranged from $277 \mathrm{~K}$ to $298 \mathrm{~K}$, and pressures ranged from atmospheric pressure to $3 \mathrm{MPa}$ was obtained based on the experimental data. The correlation can express the experimental data within $\pm 6 \%$, and express the data by Stewart and Munjal ${ }^{(4)}$ within $\pm 15 \%$.

(3) The solubility of $\mathrm{CO}_{2}$ in seawater was lower than that in pure water. It decreases with the increase in salt concentration.

(4) The solution rate of bubble in seawater is affected strongly by various parameters, such as solubility, diffusion coefficient, bubble radius, pressure, and especially temperature. The bubble solution process is enhanced by lowering the temperature: the total solution time is $30 \%$ shorter at $277 \mathrm{~K}$ than that at $293 \mathrm{~K}$ under $0.1 \mathrm{MPa}$. 


\section{Acknowledgement}

We thank the Ministry of Education, Culture, Sports, Science and Technology (MEXT), Japanese Government (Kenkyusuishin Project, 2008-2012) and Hyogo Science and Technology Association for their grants-in-aid for scientific research awarded to this research.

\section{References}

(1) Aya, I., Yamane, K., and Kojima, R., Development of $\mathrm{CO}_{2}$ Sending Method for Ocean Storage, COSMOS---Aiming at the mitigation of global warming, Technical Report of IEICE, SSS 2000-15, pp.7-12 (2000).

(2) Handbook of Chemistry, Basic II, $5^{\text {th }}$ Ed., The Chemical Society of Japan, pp.146-148, Maruzen (2004).

(3) JSME Handbook, Thermophysical Properties of Fluid, Uematsu et al. Ed., JSME, pp.487-488 (1983).

(4) Stewart, P. B. and Munjal, P., Solubility of Carbon dioxide in Pure Water, Synthetic Sea Water and Synthetic Sea Water Concentrates at $-5{ }^{\circ} \mathrm{C}$ to $25^{\circ} \mathrm{C}$ and 10 to $45 \mathrm{~atm}$. Pressure J. Chemical and Eng, Data, Vol.15, No.1, pp.67-71 (1970).

(5) Weiss, R.F., Carbon dioxide in water and seawater: the solubility of a non-ideal gas, Marine Chemistry, Vol.2, pp.203-215 (1974).

(6) Nighswander, J. A. Kalogerakis, N., and Mehrotra, A. K., Solubilities of carbon dioxide in water and $1 \mathrm{wt} \% \mathrm{NaCl}$ solution at pressures up to $10 \mathrm{MPa}$ and temperatures from 80 to $200{ }^{\circ} \mathrm{C}$, J. Chemical and Eng, Data, Vol.34, pp.355-360 (1989).

(7) Luhring, P. and Schumpe, A., Gas Solubility $\left(\mathrm{H}_{2}, \mathrm{He}, \mathrm{N}_{2}, \mathrm{Co}, \mathrm{O}_{2}\right)$ in Organic Liquids at 293.2 K, Journal of Chemical Engineering and Data, Vol. 34, pp.250-252 (1989).

(8) Liu, Q.S., Takemura, F., and Yabe, A., Solubility and Diffusivity of Carbon Monoxide in Liquid Methanol, J. Chem. Eng. Data.., Vol.41, No.3, pp.589-592(1996).

(9) Liu, Q.S., Fukuda, K., Matsuda, T., Study of Solution Process of Carbon Dioxide in Seawater, J. of the Japan Institute of Marine Engineering, Vol.41, Special Issue, pp.144-149 (2006).

(10) Hodgman, C. D., Handbook of Chemistry and physics, 44th Ed ., The Chemical Rubber Publishing Co. (1962-1963)

(11) Broecker W. S. (Translated by Nizuma, N.), Chemical Oceanography, Published by Tokyou University, pp.117 (1981).

(12) Takemura, F., Liu, Q.S., Kang, B.H., and Yabe, A., Gas Solution and Transport Process in Liquid Phase Methanol Synthesis, J. of Mechanical Eng. Lab., Vol. 48-6, 1-7 (1994).

(13) Liu, Q.S., and Fukuda, K., Transport Process of Carbon Monoxide Gas in Liquid Phase Methanol, J. of the Marine Eng. Society of Japan, Vol.35, No.10, pp.696-704 (2000).

(14) Greert F. Versteeg and Wim P.M.van Swaaij, Solubility and Diffusivity of Acid Gases $(\mathrm{CO} 2, \mathrm{~N} 2 \mathrm{O})$ in Aqueous Alkanolamine Solutions, J. Chem. Eng. Data 1988, Vol.33, pp.29-34.

(15) Funazukuri, T., and Nishio, M., Prediction of Diffusion Coefficients of Carbon Dioxide in Water and in Aqueous Electrolytic Solutions, Kagaku Kogaku Roubunshu (J. of Chem. Eng., in Japanese), Vol.21, No.4, pp.824-828 (1995). 